\title{
From the Social Shaping of Technology to the Staging of Temporary Spaces of Innovation - A Case of Participatory Innovation
}

\author{
Christian Clausen and Wendy Gunn
}

\begin{abstract}
This paper addresses recent developments within the social shaping perspective, specifically the forward-looking and political dimensions of intervening in processes of innovation. With a focus on the concept of 'temporary spaces' as an analytical framework we present a study of a case on participatory innovation concerned with indoor climate practices in the building sector. Based on an analysis of the travel and uptake of narratives derived from field studies in industrial and research environments, we discuss the role of intermediaries such as ethnographic provocations concerning user practices in the staging of these temporary spaces. While the direct uptake of qualitative knowledge on user practice in the engineering worlds of indoor climate is limited, the paper highlights the role of staging temporary spaces and intermediary objects in collaboration with stakeholders as a way of reframing conceptions of indoor climate practices.
\end{abstract}

Keywords: temporary spaces, participatory innovation, indoor climate practices

\section{Different Approaches Towards a Social Shaping of Technology}

This paper examines recent developments within the social shaping of technology research that explore temporary spaces in which innovation processes may be promoted, shaped and reshaped. Innovation increasingly takes place across sequential intersections of design and use. The research discussed here focuses on a temporary space, which is both transitory and improvisational in character. We explore the potential role of such intersections for intervention in the social shaping of technologies.

The focus of the paper is on the role of intermediaries in the movement of knowledge via participatory innovation, which emphasises particular knowledge objects, and practices. We draw upon action oriented approaches to social shaping of technology with particular attention to their discursive and political dimensions exemplified with the analytical notion of sociotechnical spaces for innovation (Clausen \& Koch, 2002; Clausen \& Yoshinaka, 2007). The notion of design labs 
(Binder \& Brandt, 2008) is incorporated as a way of addressing the staging of a temporary space, including the mobilization of findings from field and design practices.

The staging of participatory innovation practices is illustrated and analysed through a case study concerned with the social shaping of indoor climate conceptions and solutions. Shove (2003), Jaffari and Matthews (2009) and others have presented indoor climate practices as an important but difficult case for sustainable transitions due to path dependent developments sustained by dominant sociotechnical regimes. While we do not present a case of regime transition, we have been looking for new lines of inquiry concerning conceptions of user practice and whether these could lead towards a potential reframing of the way the social shaping of indoor climate solutions is being constituted.

The research involved collaboration between the Tempos project on Performing Temporary Spaces for User Driven Innovation at Aalborg University and SPIRE's research on participatory innovation at University of Southern Denmark (Buur \& Matthews, 2008; Buur 2012; Gunn \& Clausen, 2013). The aim of this particular collaboration was to trace and investigate the travel, translation and uptake of user knowledge about everyday indoor climate practices, via a series of participatory innovation workshops, into industrial organizations, engineering indoor climate research institutions, and engineering practices.

Our aim is to investigate how the movement of knowledge from local indoor climate practices to the worlds of engineering in the building industry and indoor climate research institutions may be facilitated through such interventions. Our question is concerned with the staging and politics of the design of such temporary spaces and whether these may lead to the reframing of user conceptions and their uptake in industrial and research organisations.

\section{From Social Shaping to Processes of Innovation}

From a social shaping perspective, technology is seen as an outcome of processes of negotiation between social actors, artefacts, interests, and diverse framings of problems and solutions. Previous analyses have focused on the identification of players, their visions and strategies and interactions with technological problems, solutions and technological and knowledge objects. The main concern has been with sociotechnical content and processes and has focused on settings and actors where technology can be analysed and influenced (Sørensen \& Williams, 2002; Russell \& Williams, 2002). A number of studies have focused on the synthesis of diverse types of knowledge along an unfolding trajectory of sociotechnical development (Akrich et al., 2002; Gish \& Clausen, 2013). Other studies have sought to trace the journey (or biography) of technological artefacts or management concepts while they move or extend across time and space (Hyysalo, 2010). A primary research interest has been the building of constituencies, sociotechnical ensembles, actor networks, and the processes of stabilization or destabilization within these. The social shaping perspective has often taken the outset of the sociotechnical journey as a mirror of dominant practices. Users and intermediaries (Stewart \& Hyysalo, 2008) have often been relegated to the role of appropriation, domestication and shaping a trajectory (Sørensen \& Williams, 2002). In this paper, we respond to the concerns articulated by Stewart Russell (1986) that one should not just analyse dominant 
developments, but also investigate and even demonstrate the possibilities of changing the course of events. Following Russell's attention to the uneven potential for influence between societal players, we argue for the need to make space for voices and user practices often ignored within current innovation practices.

Spatial metaphors have been widely used within a social shaping of technology tradition. For example 'laboratories', 'ensembles', 'development arenas', and 'niches' have been presented (Russell \& Williams, 2002), pointing to the ambition of developing political dimensions of the social shaping perspective. The 'development arena' (Jørgensen \& Sørensen, 2002) is presented as a metaphor for the space where political, social and technical performances related to a specific technological problem take place. A development arena is defined as "a spatial imagery that brings together heterogeneous elements that seem distant in geographical and conventional cultural space" (Jørgensen \& Sørensen, 2002: 200). This notion addresses the space that holds together settings, situated practices, and relations comprising the context and content of product and process development.

Socio-technical spaces (Clausen \& Koch, 2002; Clausen \& Yoshinaka, 2005, 2007) also encompass socio-material, political and discursive practices and emerging configurations of socio-technical ensembles and networks. Here, political dimensions are key as the spatial metaphor sensitises our attention to the inclusion and exclusion of actors, interests, and meaning as well as content in socio-technical developments. This concern mirrors key elements in the configuration of a design project as Bucciarelli (2005: 64) reminds us when he asks "Who's in? Who's out?". These developments may concern design processes on project, organizational and inter-organizational levels where intended change is the typical case. By bringing attention to political processes in the creation of boundaries delimitating but also enabling certain innovation processes, the notion of the socio-technical spaces provides a focusing instrument and sensitising device for studies of innovation and reflexive action in the social shaping tradition. Sociotechnical spaces may indeed harbour active elements like engineering practices, design approaches, project templates and management concepts which appear to play a key role in the (re-) configuration of a design or project space and the performance of its actors.

Innovation increasingly involves movements through and across a number of temporary spaces that include actors outside R\&D departments, including from other areas of corporate life, various companies in a supply chain, design bureaus and consultancies, aspects of everyday life and use practices. The notion of a design lab as presented by Binder and Brandt (2008: 116) is suggested to "capture a relevant framing of design research where stakeholders collaboratively explore possibilities [...] in a transparent and scalable process". Participants in a design lab are able to cut across organisational and institutional boundaries and include a repertoire of facilitating instruments and designed objects to enable assumptions that may otherwise be taken for granted, to be questioned. The design lab is intended to generate knowledge in some documented form and explore design spaces to engage multiple stakeholders within collaborative practices based upon different understandings of everyday use. By referring to the laboratory metaphor, the design lab also emphasises an ambition of staging a chain of ideas and designs to allow their translation into more stable innovative solutions. It is still unclear however whether 
(if at all) the outcome of such design labs results in innovations in the form of products, markets or alternative practices (Rohracher, 2003) or the formation of stable networks across institutional and professional boundaries (Jørgensen et al. 2011). Also, reports from the living lab tradition discuss challenges concerned with the scaling of local collaborative design practices into broader organisational and institutional transitions in the public sector (Carstensen \& Bason, 2010). In an analysis of three Danish user oriented intervention projects, Elgaard Jensen (2012) suggests that such projects may perform as mediators between users and development projects and challenge taken for granted assumptions concerning the user. He describes such projects as intervention-ascomposition' where the role of the mediator is seen as key focus. We see the participatory workshops discussed in our paper as a related form of intervention but use the term 'staging' to focus on the specific elements and types of interaction brought together in the workshop. The notion of temporary spaces is chosen to sensitise our analysis of the staged intervention through distributed, shifting and temporary locales for mediation across institutionalised boundaries such as between diverse organisations, knowledge practices or between development and use.

The ways in which innovative ideas are moved and shaped across temporary spaces have also been embodied in the notion of intermediaries. Howells' (2006) review of the literature on intermediaries points to the important role of intermediation in innovation and the wide and growing role of intermediaries, including brokers, third parties, and agencies that are involved in supporting the innovation process. Focus is given to the influence intermediaries have through the services they offer to suppliers in enabling knowledge to flow to and from markets and technology. The role of intermediaries as facilitators of user innovation and the linking of user innovation into supply side activities have been extensively discussed by Stewart and Hyysalo (2008). They refer to the wide ecology of diverse intermediaries playing key roles in the social learning, shaping, and configuration of emerging technologies and the importance of identifying and nurturing user side intermediaries. Innovation intermediaries are here considered as organisations or individuals attempting to "configure the users, the context, the technology and the 'content', but they do not, and cannot control use or the technology." (Stewart \& Hyysalo, 2008: 297, original emphasis). The authors emphasise that intermediaries are themselves shaped during the process as they perform as translators of interests and meaning between worlds of design and use and/or between supply, development, and emerging markets. The political dimensions of intermediaries are made explicit as they configure a space for certain kinds of meaningful interaction including considerations concerning support, access, award structures, and legitimacy.

Stewart and Hyysalo (2008) portray innovation intermediaries as persons or organisational entities, which may take on roles as actors. Callon (1991), in contrast, makes a distinction between actors and intermediaries with his focus on the intermediary objects. Here intermediaries are defined as "anything passing between actors which define the relationship between them" (Callon, 1991: 134). Actors define each other in interaction - in the intermediaries that they put into circulation. Callon identifies four main types of intermediaries: texts, technical artefacts, human beings and their competencies, and money. From a design anthropology perspective Vinck and Jeantet (1995) similarly coin the notion of intermediary 
objects, pointing at the heterogeneous nature of intermediaries as networks of social actors and objects mediating between stages in design processes. Accordingly, whether the intermediary object will perform as a stable platform for transmitting knowledge across boundaries or whether it translates or mediates knowledge in a transformative way will depend on the stability of the objects, the social actors involved and their interrelations (Vinck \& Jeantet, 1995).

From these perspectives, we have found it interesting to explore how intermediaries are staged within temporary spaces and how they perform in practice. We use the notion of intermediaries not just at social entities but also to include material and other objects. By taking intermediaries as heterogeneous assemblages or networks we intend to trace how their performance depends on how they are becoming configured. The term 'temporary space' refers to the participatory workshops discussed below, which can be seen as part of the 'design lab' approach discussed previously. The workshops were set up and staged by the research team and included the use of ethnographic provocations (Buur \& Sitorus, 2007).

It is also intended to draw attention to the more metaphorical notions of space captured in the 'development arena' and 'sociotechnical space' literature by signalling the wider range of networks engaged through the workshop process. We are interested in what kinds of knowledge outcomes are generated through purposely staged interactions between designers, design anthropologists and engineers in a temporary space and whether we can trace the uptake of knowledge into companies and organisations having a stake in designing indoor climate. How then is knowledge generated, packaged, transported and unpacked across such sociotechnical spaces from user domains to the 'home' organisations of the participating stakeholders?

\section{Staging a Temporary Space}

To illustrate the travel and/or mediation of user oriented knowledge we report on a case concerned with participatory innovation within the designing of indoor climate. Our report draws on original accounts of the workshops including working documents, published conference papers as well as our own observations as participants in the workshops and follow up interviews with project partners. The case is drawn from a Danish government funded research and development program in user driven innovation and was carried out within the SPIRE research centre at the University of Southern Denmark. The core idea of this particular project was to "take the perspective of the 'user' - the occupants of homes, offices and institutions - rather than the usual position of the engineers who design, build and control indoor climate" (Buur, 2012: 5). The project set out to investigate: a) what the notion of comfort in indoor climate means to people and how people experience comfort during their everyday use practices b) what innovation potential rests in an appreciation of peoples' everyday practices and accounts of these practices. The project exemplifies the Participatory Innovation approach developed by the SPIRE centre, which "seeks to combine the strengths of participatory design and design anthropology, while expanding towards a market orientation" (Buur \& Matthews, 2008: 268). One of the key mechanisms in a participatory innovation project is to generate knowledge about users or customers in a format that inspires company employees to reflect on the relations between product, producer role, and company identity and to generate 
business opportunities (Buur \& Matthews, 2008).

The case study enables us to trace the movement and transformation of user knowledge from user sites to confront established configurations of users in worlds of institutionalised indoor climate research and development. The groups included were: the SPIRE participatory innovation research team, engineers from an indoor climate research unit from a technical university, engineers from companies developing and manufacturing components for indoor climate solutions such as windows, ventilation and control systems, insulation material etc. The SPIRE research team organized a series of consecutive interactive stakeholder workshops and included activities such as sense making of field study material and exploration of innovation potentials. Three of the workshops were dedicated to coanalysis of material (excerpts from interview transcripts, video clips, photographic stills etc.) from field studies of indoor climate inhabitants and their practices carried out with people in their homes, offices and nurseries during the spring of 2009. The workshops were organised to instigate co-analysis between project partners and SPIRE researchers. SPIRE researchers would present a selection of surprising and provocative instances from the field sites supported by stories, design materials, quotes from interviews, and situational photographs for one or two company partners or climate research engineers. The groups were then asked to respond by participating in various activities mapping out their responses to the materials.

Engagement of the engineers and researchers in (joint) sense making of field study material reflected a key navigational decision made by the SPIRE researchers to refrain from reliance upon established engineering concepts and understandings of comfort and indoor climate. The implication was that problem framings and design strategies based in the participating organizations were only indirectly included in the sense making process and not foregrounded in workshop interactions. On the contrary, throughout the workshops, the SPIRE team encouraged the participants to engage with the material to develop a notion of indoor climate that challenged their usual perspectives.

Methods for presenting and analysing empirical material varied across the workshops, from using stories over transcripts and video clips to the use of performative tools for co-analysis aimed at analysing the framing of problems and solutions as response to carefully selected user statements. According to an account of the workshops from members of the SPIRE team (Jaffari et al., 2011) a shared understanding of indoor climate practices gradually developed across engineering and design disciplines. In this sense, a form of learning took place during a process, in which the engineers were engaged with their own future imaginings. As one engineer remarked while engaged in making sense of the field material: "if we had to see it from the user's point of view...." (Jaffari et al., 2011: 6).

An intermediate outcome of this collective learning took the form of so-called 'comfort themes'. The 'comfort themes' included a package with six small booklets aimed towards moving into the spaces of uptake inhabited by the participating engineers. They provided the engineers with statements and selected field study material and user statements to work with in their own organizations to aid the generation of innovative ideas concerning indoor climate solutions. Each 'comfort theme' was presented with a corresponding statement presenting an ethnographic provocation derived from field studies followed by 
typically three questions exploring a theme. For example in the booklet, 'Being Healthy' the authors asked: 'How would you enable people to act on and learn from their feelings of health within an indoor climate system of control?'. Underpinning another theme 'Comfort is a political construct', the conception of indoor climate as a neutral standard based on 'what the experts say' was challenged.

During the workshops the facilitator pressed for the exploration of how these 'comfort themes' might translate into innovation potentials (Gunn \& Clausen, 2013). Here the facilitator presented a selected version of the comfort themes focusing on reconceptualising agency attributed to inhabitants of indoor climate. As expected by the facilitator, some of the comfort themes caused controversial debate during the workshops bringing to the fore a clash between opinions of how user knowledge could be a source of innovation potential. These instances of conflict were an important part of the staging of the workshop whereby ethnographic provocation played a central role (Buur \& Sitorus, 2007).

A key priority in the design of workshop activities and outcomes was to challenge the dominant engineering understandings of indoor climate and avoid an engineering focus on technological objects such as climate models and building components like insulation materials, ventilation installations, control equipment or windows (Buur, 2012).

Our uptake study was initiated in the wake of the development of the comfort themes in order to a) improve the understanding of stakeholder positions and potential outcomes in terms of innovation and $b$ ) to inform the navigational process of the remaining workshops. Our interviews sought to trace the indoor climate end user voices in the format of narratives of user practices from the participatory workshops into the realms of companies manufacturing building components and an established indoor climate research environment. We asked how user knowledge derived from field studies interacts with systems of expert and generalized knowledge in the generation of innovation potential. Our aim was to analyse how the qualitative user knowledge was taken up, rejected or transformed in the participating organizations and their practices. In-depth 2:1 semi-structured interviews were carried out by the authors with six engineers from three companies ${ }^{1}$ from the Danish building sector and a university based climate research centre - all being active in the SPIRE participatory innovation workshops. During the interviews the engineers were asked to describe the characteristics of the dominant knowledge practices of their organizations and compare them with the kinds of knowledge received through collaboration with SPIRE researchers. As a next step we asked the interviewees to comment on and relate to the comfort themes in the form of photographic sheets showing a series of video stills and statements from the differing field sites of people's practices of indoor climate use. As described above, the company partners had been previously introduced to the materials in various formats throughout the SPIRE workshops. During the interviews, the authors referred to the comfort themes as a way to remember what individual participants had learned through participating in SPIRE workshops. Specifically, we were interested in how perceptions of the innovation potential of end user indoor climate practices changed as a result of the collaborative activities and how (if at all) the project partners had been able to pursue within their organizations what was learned during their participation in the workshops. 


\section{Challenging Model Based Research Practices}

Three of the engineers participating in the workshop series were affiliated with a Danish university based research centre for indoor climate. The research centre for indoor climate has been an important player in the development of research based indoor climate models and represents an internationally highly recognised research environment. The centre promotes itself as an important provider of knowledge to governmental regulation of building requirements as well as industry standards and practices in indoor climate.

During our interviews, the engineers from the research centre stressed how different the knowledge practices at the centre were from the local and qualitative knowledge they were confronted with in the SPIRE workshops. Here their modelling practices stand out as a main reference point when comparing the differences between knowledge practices. The ambition of climate model research has typically been to describe the general relations between certain indoor climate factors (often temperature, air quality, light and noise) and a measure of general satisfaction with the indoor climate. The first climate models were based on laboratory experiments with test persons in an artificial, but controlled environment. Here, the inhabitants of indoor climate were represented as a generalised human being as made up across the variety of a test sample.

Over the years, such models have provided an important frame of reference for building requirements and engineering standards in industrialised countries. These models have been criticised (Shove, 2003; Jaffari \& Matthews, 2009) for framing a particular knowledge base, fuelling the development of an industrial indoor climate control regime based on uniform global industrial standards for indoor climate solutions independent of local climate and the local cultures.

As one senior engineer from the research lab said:

Our group has always been thinking about humans in our research, and have involved people in our research by asking them how they perceived indoor climate [...]. But, even if we ask people what they feel, it is another question entirely what they actually do to control their environment. This opens up the question: Should we design a centrally controlled indoor climate environment or should we delegate the control to people? [...] This is an important topic in our research community, as it is now, it is a one size fits all, and it seems like there is an increasing tendency to challenge this.

While this statement points towards configuration of key social and political dimensions in modelling work, it is also clear that the tradition has a tendency to detach ideas of the social from engineering design practices (Harvey, 2010) and even to remove any space in the models for certain kinds of qualitative knowledge. This has resulted in an understanding of the indoor climate user as being passive rather than active while negotiating indoor climate.

As mentioned previously, the SPIRE indoor climate research project was viewed as an opportunity to extend the research agenda of indoor climate modelling and further develop the understanding of social aspects of indoor climate. Over the last decades, traditional factors defining indoor climate have been gradually extended and studied in detail based on quantitative methods. Compared to this tradition, analysis based on field studies outside controlled test sites was welcomed as a 
new approach to include more knowledge on 'the human behaviour side' of indoor climate. Here it is important to remember emphasis is placed upon an understanding of human behaviour based on behavioural psychology. Similar conceptions are reported from engineering practices concerned with users within the energy sector (Løgstrup et al., 2013).

Our senior engineer from the research lab continued to discuss the difficulties of incorporating what was learned within SPIRE workshops in his research investigations:

What we have learned from SPIRE workshops here is also to look at end users as individuals. We have to be careful with generalising across individuals, and I am convinced that people are different. But it is difficult to judge how much this lesson feeds back on our research at this moment. We will have to see...

Similarly one of the younger researchers from the same lab commented:

For a long time, the climate models developed here were based on laboratory experiments with test persons in an artificial but controlled environment, but this did not represent real life situations. Recently, we have become more interested in human behaviour because you cannot explain or predict energy consumption in a house with natural ventilation without taking the human aspect into consideration.

Here, there is a clear indication that a movement in knowledge practice would be possible based on a conscious linkage between the new energy saving agenda and a challenge of the current generalised user construction accentuated by the SPIRE workshops. Field studies may, according to the lab researchers, add new dimensions to understanding how people are using buildings and why they behave as they do, how they are affected by and how they influence indoor climate. But again, the qualitative field study material was mainly seen as providing input to define new research hypotheses. However it was important for the lab team to remember that, "[i]n the end we will have to test these hypotheses through quantitative surveys".

While the younger research lab engineer experienced the SPIRE workshops as highly revealing and inspiring for future research, he also recalled the difficulties in following an ethnographic approach.

With our engineering background we were actually not really able to interpret the video stills, video clips and narratives from field studies but were dependent upon the SPIRE researchers [...]. These experiences have opened up for some movements in our knowledge practices... I have learned a lot and I will certainly take up the qualitative methods while conducting interviews as part of my future projects, as it gives a much better understanding of why people act as they do.

Key dimensions in these engineers' construction of an image of indoor climate users have been based on a research design focusing on the selection and distribution of test persons or survey respondents and a search for factors or parameters expected to have measurable effects on human wellbeing or on performance indicators. These laboratory settings form a certain kind of epistemic culture (Knorr-Cetina, 2001) allowing only certain framings of research questions. Often these practices, according to the younger researcher, assume an application of the results in specific 
engineering design practices based on single factor design requirements.

The current indoor climate modelling practices are furthermore an integral part of a larger engineering system with its infrastructure defining a chain of user constructions, indoor climate definitions and practices of usage in regulation and engineering design. This particular epistemic culture signifies the relevance of research as to whether it can be successfully translated into design recommendations in engineering practices and/or by defining a building design category. But the offering of clear cut design recommendations also poses some dilemmas as indicated by one senior research lab engineer:

The industry has been asking us to combine the diverse climate dimensions into one single measure, I don't know whether it is feasible or at all possible.

A younger research lab engineer working in the same lab supported this:

Building engineers often expect a single figure in order to make design easier for themselves, but they often fail to understand the limitations and underlying complexity of indoor climate models.

Here, our young engineer refers to practice in certain engineering worlds, where engineers are reluctant to take on design responsibility and prefer to automate decisions or make rule based decisions.

We also registered a movement away from the current and prevailing generalised understandings of end users of indoor climate. But this movement was rather vague and constrained by established ideas of producing single dimensions and even a single figure as a design recommendation and the expectation of providing explanations and predictions of user behaviour. In this sense the user is still reduced to a variable in the engineering calculation. And the idea of seeing the user as a co-constructor/designer of indoor climate not to say a key player or subject in the control of indoor climate solutions can hardly be addressed within such a practice.

\section{Marketing Strategy Confirmations}

Similar difficulties in taking forward the distinctive perspective from the workshops can be seen in the context of inputs to product development and marketing. The engineer participating in the workshop from the skylight window manufacturer is located in a group of engineers and architects at the company headquarters. Their task is to provide technical marketing support to a global sales organization of a large $(10,000$ employees) Danish multinational company and to provide analysis and knowledge support to management decisions. The company is specialized in the development, manufacturing, marketing, and sales of one product - a skylight window - in a number of variants. This particular product has a strong position in a niche market globally and the company is the main branch of a leading Danish group in the building sector.

When the engineer from the skylight company compares the knowledge traditions of the SPIRE group and the company, he first of all refers to the unique company history and its organizational culture:

This company has a very long tradition for quality and trustworthiness. Every statement from the company, therefore, has to be based on sound evidence. And here I mean based on technical arguments or on numbers... Only quantitatively based arguments are recognised as valid in top management and in the sales and marketing department. The 
same is the case when we want to present our point of view in standardisation committees and revision of building regulations... We have a strong relation to research institutions like the Danish university based research centre for indoor climate where it is important to be able to base your arguments in research based data.

Many of the engineers in the company are recruited from the Danish research centre for indoor climate previously discussed and have similar engineering backgrounds and perceive arguments originating from this research as the hard currency in political arguments for the building industry and its regulatory bodies. This observation underlines the existence of shared knowledge practices in an engineering world cutting across several organizational borders. Our engineer from the skylight engineering company expresses a strong awareness of these rules for making accounts in the organization. He was also aware, however, that the same rules were a strong barrier for the dissemination and sharing of knowledge from the SPIRE user oriented project in the organization.

On the other hand, our engineer is also on the lookout to bring new approaches into the organization and tries to make an opening for anthropological knowledge by stressing the important role scientific institutions play in producing credibility in his organization. As he said:

I noticed that the methods SPIRE used were also based on scientific arguments, and I like the idea that more university units contribute to research in indoor climate.

Actually, the company had recently employed an anthropologist to do user studies, which indicates that several knowledge practices could potentially coexist in his organisation though the value of these accounts might vary according to circumstances.

This diversity and co-existence of multiple practices was also evident as the company is not a knowledge producing research unit, but an organization geared to promote a product by seeking the best support of scientific arguments for the marketing of a product. The strategic implication is to seek a mutual alignment between product features, the dominant sales argument and current indoor climate discourse. The implication being that the main framing of how the user oriented qualitative knowledge is received stems from the product. The skylight window engineer presented the company's interest in the indoor climate project:

You have to understand, we are not selling windows, we are selling daylight and fresh air.

Accordingly, his immediate comment to the field study informant statements picked from the comfort themes was:

I was so happy to see the picture of the woman standing there with the open window and the statement, 'Indoor climate does not stop at the window'. But also the statement that 'indoor climate is something you make'. These statements are quite important to us, because it confirms that people want to be able to open their windows, and that it is an important part of the indoor climate.

In this case, the user articulations are closely associated with the skylight manufacturers' current marketing strategy in so far as it underlines the very framing of their product. Consequently the engineer 
was receptive to the SPIRE approach, as there happened to be an alignment between differing perspectives on this issue.

The engineer from the skylight manufacturer clearly appreciated the engagement with qualitative knowledge, but as he also points out, there seems to be a very limited uptake in the wider organisation. Especially when it comes to the identification of innovation potential, the engineer has difficulties in pointing out where innovation takes place in the organisation. In this instance, field based material is most often confined to address, and to be appreciated in, the marketing processes and not in the front end of innovation. The company had a small frontend unit focusing on the development of new business areas, but this unit did not seem to pay much attention to findings from collective sense making generated within the SPIRE workshops.

\section{Future Business Opportunities}

The mechanical window manufacturer is part of the same multinational concern as the skylight manufacturer and the framing of their product is expressed in similar terms: 'We are selling natural ventilation'. This means that they see their main competitors as companies promoting and selling mechanical ventilation and consequently are on the lookout for arguments supporting natural ventilation solutions.

During the interviews we realized that the reception of user narratives and workshop exchanges did, in fact, lead towards the generation of ideas for further development of existing product programmes and services. This was most obvious when our engineer from the window control manufacturer began to discuss his company's focus on selling natural ventilation. His future business proposition was concerned with the control of indoor climate in office buildings, as the company manufactured and offered control systems and motors to operate windows. The definition of indoor climate is important here as it enters business calculations and directly informs the design criteria applied in the design of solutions. As he said:

It is free of cost to open the windows compared to operating a mechanical ventilation system so we represent a different philosophy based on natural ventilation.

Still, while the philosophy is based on natural ventilation, by offering a system perspective, natural and mechanical ventilation are often balanced in order to be able to meet the required indoor temperature in all seasons. In order to support the concept, the company has developed a configuration model where the effect of a number of design variables such as room size, façade design, temperature, and ventilation are simulated and compared to a calculated temperature and air quality ( $\mathrm{CO}_{2}$ content) distribution.

The engineer from the window control manufacturer emphasizes the diverse origins of their knowledge: governmental prescriptions, property owner demands, and experiences from the practical implementation and use of their systems. He points to the 'optimization department' as the company's primary collector of user insights and experts in making contact to real world settings. One important lesson for the engineer in control manufacturing drawn from the indoor climate project is concerned with the conceptualization of the user. The company would normally negotiate solutions with architects, engineers, and property owners. After installation, private end users, typically represented by facility managers in an office building or school, would be instructed 
on how to use the system. Here, facility managers are expected to fulfil a mediating role between end users and designers of indoor climate solutions. But, as SPIRE field studies attended to where, when, how and why people negotiate indoor climate on a daily basis, our engineer observed that there could be a conflict between the facility managers' more economic view and the inhabitants' idea of comfort and the ability to control it. Again, meeting with traces of how people negotiate indoor climate in their everyday situated practices of use appeared distant from the worlds of engineering. As one engineer observed,

I was surprised to see that the users often do not know how to work the systems.

This observation leads the engineer to further consider a need in his organization to incorporate broader local user knowledge in the configuration of ventilation solutions and how to convince the owner and 'administrators' of the value of such a user involvement. A further idea would be to consider the innovation potential in the adoption of a user-oriented service related to the advice on configuration and implementation of ventilation systems. A less radical perspective concerning user involvement - which the engineer from the ventilation control manufacturer saw as more realistic - would be to inform users on the system functionalities and how they might control the indoor climate more efficiently.

However, the observation from the field studies attracting most attention from the SPIRE project partners - and clearly indicated in the comfort themes - was the limited possibilities for control of indoor climate by the end users. Consequently, the window control manufacturer could imagine developing new control devices including temperature, $\mathrm{CO}_{2}$ and humidity, and also how a new device might support an exchange of different views and perceptions of indoor climate quality and control. A major barrier for innovation of this type, according to the engineer from the window control manufacturer, is that company product development in this area is purely market driven. The implication being that a demand has to be demonstrated through company sales channels before a development is initiated.

\section{New Collaborations Across Businesses}

One of SPIRE's project partners was head of development from an international insulation manufacturer. She was concerned with the use of their products and how the use and markets could be extended. Continuously changing building regulations stipulating higher demands for energy saving were, of course, seen as an important driver for the general extension of the market for building insulation. Her position as head of development offered a more direct link to innovative activities compared to other partners involved in the SPIRE project.

Still, she pointed at the limited innovation in new products within the building sector and how many companies in this sector only innovate along existing paths of development. Ambitions to break with these dependencies seem to have very limited opportunities. These strong path dependencies (Garud \& Karnøe, 2001) based on single dominant product designs and concerns for the protection of established market relations are paralleled with the highly embedded institutionalized knowledge practices in the building sector and its regulation in the western world. The implication of this being that the development of new business areas are hardly considered, in particular if the 
assumed business models involve multiple stakeholders in the designing of indoor climate.

Based on these observations, our engineer from the insulation manufacturer suggested a different way to overcome innovation barriers in the sector. She pointed to the ongoing dialogue in the SPIRE workshops as an opportunity for developing a new platform for innovative collaboration including research and development activities between the diverse companies. In this sense, the insulation manufacturer's representative understood participation in collaborative workshop activities as a means of aligning differences concerning innovation potential across the industry.

The engineer from the insulation manufacturer also recognized the challenges faced because of a limited sharing of knowledge in the wider building sector and the difficulties in making diverse products (insulation, windows etc.) fit together to form improved indoor climate solutions. Many players in the sales channels, especially the timber yards, and many small construction companies do not even take up the engineering knowledge available, never mind knowledge generated through people's everyday situated practices. Accordingly, by finding ways of working together across companies it should be possible, she suggested, to develop constructive advice and coordinated concepts. These could include more holistic building regulations, a new coordinated platform or standard for combining and fitting diverse construction elements in a cross-company recommendation of how to achieve a 'good indoor climate for people to inhabit'.

From this position, the end user is not just a variable social component separated from the material world but a competent player who innovators may relate to. Still, while the user is implicated in the innovative process, the user is not necessarily intended to have an active role, but rather to be a figure to be educated and informed.

\section{Uptake of User Oriented Knowledge}

The previous sections have discussed how a temporary space was created and how it enabled partial connections between everyday situated practices of negotiating indoor climate of the individual private end user with individual engineers performing roles in the worlds of indoor climate engineering. We have described how the SPIRE researchers in close interaction with engineers within this temporary space staged a number of intermediary objects, in the form of 'comfort themes' - forms of knowledge embodying narratives based on a practice oriented perspective on indoor climate and its inhabitants. The aim was to instigate reflexivity upon indoor climate engineering research and design practices and provoke reflection challenging current engineering conceptions of the user within indoor climate research, manufacturing, and business towards alternative future design of indoor climate. We have then traced the uptake of aspects of these comfort themes by following the engineers participating in this temporary space back to their home organisations.

Our interviews showed how the engineers' unpacking of the 'comfort themes' within the organizational and engineering worlds were highly selective and how the received understanding of user practices was reinterpreted and translated in the light of established engineering knowledge practices. In particular, the assumptions of the end users role in the design of indoor climate and the role end users can (or could) play in designing indoor climate were challenged. But, while our engineers readily engaged in 
a deliberation of the possibilities for an increasing engagement with end users appreciating these as competent players with relevant knowledge, the engineers were rather hesitant about the possibilities of assigning users more active roles in the design of indoor climate solutions. The engineers we interviewed mainly related comfort themes to (enact) existing products, marketing, and business strategies and infrastructures of engineering models and systems. While this is not surprising we observed a variety of patterns of uptake of qualitative understandings of user practices. In cases where the user practices identified confirmed strategic concerns in the company or research unit, and where user knowledge was in line with dominant framings, as in product marketing, we found an unproblematized application of the 'new' user insights.

By reinterpreting the knowledge base of established user constructions, a number of current framings of users embedded in institutional structures and knowledge infrastructures and their associated taken for granted assumptions became challenged through the engineers' participation in the temporary space. A reframing of what innovation could be has only taken place in the few cases where something is at stake such as when the engineers express the difficulties of designing energy saving solutions across unfitting products and unaligned business strategies or the controversies related to the development of new building regulations. In these cases the engineers' articulation of ideas of reconfiguring actors and infrastructures could be an indication that some movement in terms of reconceptualising the end user has occurred as a result of participating in SPIRE workshops. Generally, we found the movements in understandings of users and use practices within the organisations to be rather limited. It seems like the participating engineers' own conceptions were highly challenged, but their new insights clashed with established practices and made changes in engineering practices in the project partner organizations difficult if not impossible.

How, then, did the 'comfort themes' discussed previously establish a broader way of thinking in the organizations about the end user of indoor climate and the potential for innovation within the designing of indoor climate? In the following, we discuss these issues by focusing on the role and configuration of the temporary space, the nature and design of the intermediary objects involved in collaborative activities, and movement of the inscribed knowledge into subsequent design spaces along a potential innovation journey.

\section{Temporary Spaces}

Temporary spaces as a notion is inspired by the design and innovation oriented concepts like 'design labs' (Binder \& Brandt, 2008) and 'participatory innovation' (Buur \& Matthews, 2008) while also drawing on the more analytical stance highlighted in concepts such as development arenas and sociotechnical spaces. The notion of temporary spaces is especially aimed at sensitising our attention towards the configuring, political and discursive elements of distributed spaces for user oriented innovation outside or on the fringes of institutionalised practices. Key configuring elements of a temporary space resemble the sociotechnical and innovative space described by Clausen and Yoshinaka (2007) and Brønnum and Clausen (2013). In our case this would encompass:

1. The defining content and meaning of the space as it is defined in the purpose and idea of the project set-up where the participants are 
enrolled. This includes 'taking the perspective of the user rather than the usual position of the engineers in designing indoor climate solutions'.

2. The inclusion of participating engineering domains related to indoor climate, company partners from component manufacturers, and engineering consultants and the non-inclusion of 'real' users.

3. The institutional underpinnings as a public funded research and development project within the highly profiled Danish government, 'User Driven Innovation' programme and hosted by a university research team.

4. The specific re-presentation of field studies in the form of design materials involving traces of user voices and practice narratives into the space.

5. The design approaches to the staging of interactions, the methods employed, and competences of the facilitators setting up the space.

6. The navigation of the discourse and political agenda defining meaning and content of the space.

7. The collaborative design of intermediary objects, where the comfort themes turned out to be a key focusing device for staging interactions in the temporary space and the wider travel of the gained insights out of the space and into the partner organisations with the participating engineers.

Few studies have been concerned with how such spaces are created and become configured. In their analysis of four distributed user-inclusive innovation communities, Heiskanen et al. (2010: 508 ) conclude that successful innovation communities demand a certain level of commitment within which a mutually beneficial alignment of resources and interests falls into place. Their cases show how much effort it takes to sustain even a limited collectivity. While these innovation communities mostly draw on already established sustained communities of practices, the innovative space we have been studying was highly temporary and only sustained through a limited number of meetings within the timeframe of an externally funded project. Furthermore, the indoor climate space was deliberately set up as an intermediary project intersecting and with the purpose of linking together engineering worlds from a diversity of industrial organisations with their vested strategic interests as well as diverse research traditions within indoor climate. Although the engineering participants were part of the same indoor climate engineering community of which several shared educational backgrounds, the SPIRE project partners represented just corners of larger organisational and institutional networks. Still, they had a shared interest in exploring indoor climate user practices, as this was considered relevant within the societal expectations of reducing energy consumption to which their organisations were inclined to respond.

A temporary space refers to an assembly of actors from a diversity of worlds being able to foster significant but limited steps along a potential, innovative journey (Garud et al. 2013). These temporary spaces can hardly be expected to synthesise or transform engineering knowledge with a practice-based view of indoor climate use into full-blown innovative ideas for new products, systems or services. But, as in our case, they may include designing and framing intermediary objects which move forward ideas or convey knowledge being able to travel to other design areas for further innovative treatment and co- 
development iterations. What we have seen in the SPIRE case is how a temporary space has problematized indoor climate conceptions and initiated a process towards raising awareness of the limitations of current knowledge infrastructures and constructions of users, which currently constrain and determine development activities in doing business. In this sense an outcome of this particular space may be the opening up of certain possibilities through the co-existence of several constructions of users and framing of design problems and alternative designs in the future compared to the single engineering model based quest for certainties which have been the norm.

Returning to Stewart Russell's (1986) concern for political intervention in innovation, we have to admit that our case does not directly 'demonstrate the possibility of changing the course of events'. In line with Elgaard Jensen (2012) we demonstrate that dominant conceptions of the user has been challenged, but we cannot point at direct changes in design or knowledge practices in the participating companies. In many ways our findings echo studies of innovative work in larger mature companies (Dougherty, 2008; Brønnum \& Clausen, 2013; Gish and Clausen, 2013) where uptake of ideas from users to $R \& D$ or knowledge transfer across knowledge domains is indeed difficult and demand a sustained effort over time, especially if these ideas are challenging taken for granted and entrenched knowledge practices. To accomplish changes in practice, a problematization of user conceptions have to be translated into ideas and product concepts through several subsequent temporary spaces of design. The concept of temporary spaces is offered as a sensitising device to help reflect on and improve strategies for staging such interlinked interventions. Here, the design of intermediaries and configuration of the temporary spaces including the navigation of interests, established knowledge infrastructures, and pressing societal discourse and strategic considerations should be of concern.

\section{Nature and Design of Intermediary Objects}

What can we learn from the staging of the temporary space of the workshops and its configuration? How did the 'comfort themes' with their inscribed practiceoriented framing of indoor climate perform as an intermediary object moving across these diverse worlds? While the intermediary seems to perform a successful transformation of established user understandings within the temporary space, further attempts to reframe the relation between the private end user and the SPIRE partner organizations operating in the worlds of indoor climate engineering seem much less successful. Similar observations stem from studies in other sectors and organizations even where concerns for user practices are articulated (Løgstrup et al., 2013; Brønnum \& Clausen, 2013).

The knowledge inscribed in the proposed 'comfort themes' from the workshops were not taken up as a simple and uniform appropriation of 'sticky' user knowledge (von Hippel, 2005) or as the outcome of building relations with users (Heiskanen et al., 2010). Instead, the comfort themes we have discussed in this chapter instigate reflections on the notion of the user(s), which seems to be constructed and framed in diverse ways, mirroring the specific spaces of uptake. User constructions are abstractions, but these abstractions are constructed and appear as contestable terrain, whereby actors from the diverse companies and the indoor climate research institution seek to position themselves according to how they frame professional or strategic interests. They are not just neutral 
elements of organizational intermediaries that mediate between spaces of use and design (Stewart \& Hyysalo, 2008) but rather travelling knowledge objects based on narratives and video stills of what users do while negotiating indoor climate.

The 'comfort themes' can be viewed as heterogeneous intermediary objects (Vinck \& Jeantet, 1995) where the stability of the object depends on the staging and ongoing stability of the participants engaged in the temporary space. While being influenced by the participating engineers from the temporary space into the partner organisations, SPIRE researchers and memories of others everyday use practices become more distant while the engineering, organisational and research practices became evermore present. The level of movement of knowledge such intermediary objects can perform varies substantially across the diversity of organizational worlds. Organizational worlds where something is at stake (business opportunities, external pressures for reduction of energy consumption etc.) seem to be more prone to influence what can be taken up concerning 'the implications for design' of practice oriented 'comfort themes' (Dourish, 2006, 2007). These findings resemble Carlile's (2002) observation that boundary objects in product development are only being effective (transformative) in cases where something like a political issue or meeting a performance goal is at stake.

\section{The Travel Along Design Spaces}

The unfinished nature and interpretative flexibility of the comfort themes also allowed for a diversity in the uptake of a practice oriented user perspective in the different organisational worlds. This becomes visible when we turn to the way our engineers relate to and enact knowledge objects and relations in their organisations. While they explain what the practice oriented 'comfort themes' can mean to their organisations, they simultaneously draw our attention to how their role, including their bounded possibilities, are configured as part of their world of uptake including its specific frame of references. They make associations with certain actors and specific parts of knowledge objects to define their space. A number of significant diversities can be observed in the commitment of the engineers to their respective worlds of uptake. They vary in their historically developed knowledge practices, in the discourses they refer to on user constructions (Akrich, 1995), in the role assigned to diverse knowledge objects, and to other groups of people in their respective worlds.

Co-analysis of interview materials indicates a number of commonalities in the engineers' understanding across their social worlds (Clarke \& Star, 2008) in the sense that they refer to common discourses on indoor climate definitions and the overall needs for reduction of energy consumption. The engineers indicate the existence of a shared engineering infrastructure (Clarke \& Star, 2008: 115) across the diverse organisations, which tend to reproduce a certain construction of design-use relation. The chain of knowledge flow originating from research negotiated in the standardisation committees, informing governmental building regulations to end up as design requirements in the engineering design of indoor climate systems and building solutions, indicates a common reference point in a technological infrastructure. Some of the engineers involved in the temporary space questioned the linear assumptions behind such an engineering infrastructure, pointing at its proven inability to respond to current challenges on the use side and to a lack of interest in end users' difficulties in negotiating indoor climate products and systems of control. 
Another engineer involved pointed at the missed opportunities of learning from experiences in the user end of the supply chain and the possibilities for exchange of knowledge(s) along the chain. In other words, the limited movement in knowledge practices can be partly explained by how the engineers refer to a practice across the social worlds of design and use, where problem definitions at the engineering end are given much greater attention than considering a design space in the user end of the relation.

\section{Conclusion}

We have shown how a design staged intervention in indoor climate design in the form of a temporary space was set up by a research team and how it helped challenge and, under certain circumstances, even reframe existing engineering and model oriented user conceptions towards a more user practice oriented perspective. But our study also shows that, due to strong path dependent innovative practices in the participating organisations, a direct uptake of a different understanding of user practices beyond the temporary space proved limited. Path dependent innovative practices, business strategies and dominant designs add to the lack of relevant spaces for innovation within, or across, the participating organizations where supposedly 'new' insights might be turned into 'new' product ideas.

The temporary space is suggested as a sensitising concept in the staging of the minor but important steps involved in design staged interventions. By pointing at the role of temporary spaces and intermediary objects we have argued that intermediaries can be subject to ongoing changes in both the design process and the interventions made, while at the same time remain responsive to the changing and specific conditions across different sites of indoor engineering practice. The design of intermediary objects in close interaction between fieldwork methods, design practices and engineering oriented knowledge practices, together with key stakeholders, seems important for the configuration of temporary spaces and the reframing of user conceptions. It appears that the configuration of the temporary space and the design of intermediary objects are closely intertwined and mutually dependent.

\section{References}

Akrich M (1995) User Representations: Practices, Methods and Sociology. In: Rip A, Misa J \& Schot J (eds) Managing Technology in Society: The approach of Constructive Technology Assessment. London: Pinter, 167-184.

Akrich M, Callon M \& Latour B (2002) The Key to Success in Innovation, part II: The Art of Choosing Good Spokespersons. International Journal of Innovation Management 6(2): 207-225.

Binder T \& Brandt E (2008) The Design Lab as Platform in Participatory Design Research. CoDesign 4(2): 115-129.

Brønnum L \& Clausen C (2013) Configuring the Development Space for Conceptualization. In: Lindemann $\mathrm{U}$ et al. (eds) Proceedings of the 19th International Conference on Engineering Design (ICED13) Design for Harmonies. Seoul: Design Society, 171-180.

Bucciarelli LL (2005) Design Collaboration: Who's in? Who's out? In: Binder $\mathrm{T}$ \& Hellström M (eds) Design Spaces. Helsinki: Edita Press, 64-71.

Buur J \& Matthews B (2008) Participatory Innovation. International Journal of Innovation Management 12(3): 255-273.

Buur J \& Sitorus L (2007) Ethnography as design provocation. Ethnographic Praxis in Industry Conference Proceedings (EPIC 2007). Keystone, CO, USA: EPIC, 140-50. 
Buur J (ed) (2012) Making Indoor Climate: Enabling People's Comfort Practices. Sønderborg: Mads Clausen Institute, University of Southern Denmark.

Callon M (1991) Techno-economic networks and irreversibility. In: Law J (ed) A Sociology of Monsters: Essays on Power, Technology and Domination. London: Routledge, 132-160.

Carlile P (2002) A Pragmatic View of Knowledge and Boundaries: Boundary objects in new product development. Organization Science 13(4): 442-455.

Carstensen HV \& Bason C (2010) Powering Collaborative Policy Innovation: Can Innovation Labs Help? The Public Sector Innovation Journal 17(1): Article 4. Available at: http://www.innovation.cc/ scholarly-style/christian_bason_v17ila4. pdf (accessed 22.9.2013).

Clarke AE \& Star SL (2008) The Social Worlds Framework: A Theory / Methods Package. In: Hackett EJ et al. (eds) The Handbook of Science and Technology Studies. Cambridge, MA: MIT Press, 113138.

Clausen C \& Koch C (2002) Spaces and Occasions in the Social Shaping of Information Technologies. In: Sørensen $\mathrm{KH} \&$ Williams R (eds) Shaping Technology, Guiding Policy: Concepts, Spaces and Tools. Cheltenham: Edward Elgar, 223-248.

Clausen C \& Yoshinaka Y (2005) Sociotechnical spaces - Guiding Politics, Staging Design. International Journal of Technology and Human Interaction 2(3): 44-59.

Clausen C \& Yoshinaka Y (2007) Staging Sociotechnical Spaces: Translating across Boundaries in Design. Design Research 6(1-2): 61-78.
Clausen C, Pedersen S \& Yoshinaka Y (2012) Facilitating and navigating user knowledge in an organizational context. Proceedings of the $12^{\text {th }}$ Participatory Design Conference. New York: Association of Computing Machinery (ACM), 41-45.

Dougherty D (2008) Managing the 'Unmanageables' of Sustained Product Innovation. In: Shane S (ed) Handbook of Technology and Innovation Management. Hoboken: John Wiley and Sons Ltd., 173193.

Dourish P (2006) Implications for Design. Proceedings of the SIGCHI conference on Human Factors in computing systems. New York: ACM, 541-550.

Dourish P (2007) Responsibilities and Implications: Further Thoughts on Ethnography and Design. Proceedings of DUX'07. New York: ACM, 2-16.

Elgaard Jensen $\mathrm{T}$ (2012) Intervention by Invitation: New Concerns and New Versions of the User in STS. Science Studies 25(1): 13-36.

Garud R \& Karnøe P (eds) (2001) Path Dependence and Creation. London: Lawrence Erlbaum Ass.

Garud R, Tuertscher P \& Van de Ven A (2013) Perspectives on innovation processes. The Academy of Management Journal 7(1): 775-819.

Gish L \& Clausen C (2013) The framing of product ideas in the making: A case study on the development of an energy saving pump. Technology Analysis and Strategic Management 25(9): 1085-1101.

Gunn W \& Clausen C (2013) Conceptions of Innovation and Practice(s): Designing Indoor Climate. In: Gunn W, Otto T \& Smith RC (eds) Design Anthropology: Theory and practice. London: Bloomsbury, 159-179. 
Harvey P (2010) Producing data to shape a better world: Mathematics and engineering in southern Peru. Audio File. The Detachment Collaboratory: Interdisciplinary Experiments in Disconnection. Available at: http:// detachmentcollaboratory.org/ (accessed 23.5.14).

Heiskanen E, Hyysalo S, Kotro P \& Repo P (2010) Constructing innovative users and user-inclusive innovative communities. Technology Analysis and Strategic Management 22(4): 495-511.

Howells J (2006) Intermediation and the role of intermediaries in innovation. Research Policy 35: 715-728.

Hyysalo S (2010) Health Technology Development and Use. London: Routledge.

Jaffari S, Boer L \& Buur J (2011) Actionable Ethnography in Participatory Innovation: A Case Study. Proceedings of The 15th World Multi-conference on Systemics, Cybernetics and Informatics, vol. 3. Orlando FL: International Institute of Informatics and Systemics, 100-106.

Jaffari S \& Matthews B (2009) From occupying to inhabiting - A change in conceptualising comfort. IOP Conference Series: Earth and Environmental Science 8(1): 1-14.

Jørgensen U \& Sørensen O (2002) Arenas of Development: A Space Populated by Actor-worlds, Artefacts, and Surprises. In: Sørensen KH \& Williams R (eds) Shaping Technology, Guiding Policy: Concepts, Spaces and Tools. Cheltenham: Edward Elgar, 197-222.

Jørgensen U, Lindegaard H \& Rosenquist $\mathrm{T}$ (2011) Engaging Actors in Co-Designing Heterogeneous Innovations. In: Culley SJ et al. (eds) Proceedings of the 18th International Conference on Engineering Design (ICED 11): Impacting Society through Engineering Design. Lyngby/ Copenhagen: Design Society, 453-464.
Knorr Cetina K (2001) Objectual practice. In: Schatzki TR, Knorr Cetina K \& von Savigny E (eds) The Practice Turn in Contemporary Theory. London: Routledge, 175-188.

Løgstrup LB, Nelson MM, Mosleh WS \& Gunn W (2013) Designing anthropological reflection within an energy company. In: Proceedings of Ethnographic Praxis in Industry Conference, EPIC 2013, 15th-18th September, London, 91-103. Available at: http://epiconference.com/2013/ sites/default/files/EPIC-Proceedings.pdf (accessed 27.9.13).

Rohracher H (2003) The role of users in the social shaping of environmental technologies. Innovation 16(2): 177-192.

Russell S (1986) The Social Construction of Artefacts: Response to Pinch and Bijker. Social Studies of Science 16(2): 331-346.

Russell S \& Williams R (2002) Concepts, Spaces and Tools for Action? Exploring the Policy Potential of the Social Shaping Perspective. In: Sørensen KH \& Williams R (eds) Shaping Technology, Guiding Policy: Concepts, Spaces and Tools (Cheltenham: Edward Elgar): 133-154.

Shove E (2003) Comfort, Cleanliness and Convenience: The Social Organization of Normality. Oxford: Berg.

Stewart J \& Hyysalo S (2008) Intermediaries, Users and Social Learning in Technological Innovation. International Journal of Innovation Management 12(3): 295-325.

Sørensen KH \& Williams R (2002) (eds) Shaping Technology, Guiding Policy: Concepts, Spaces and Tools. Cheltenham: Edward Elgar. 
Vinck D \& Jeantet A (1995) Mediating and Commissioning Objects in the Sociotechnical Process of Product Design: A conceptual approach. In: Maclean D, Saviotti P \& Vinck D (eds) Designs, Networks and Strategies, vol. 2, COST A3 Social Sciences. Bruxelles: EC Directorate General Science R\&D, 111129.

von Hippel E (2005) Democratizing Innovation. Cambridge MA: MIT Press.

\section{Notes}

1 Company A was a large Denmarkbased multinational skylight window manufacturer; company B was a Danish mechanical window manufacturer specialised in natural ventilation and control systems; and company $\mathrm{C}$ was a Danish subsidiary of a large European insulation manufacturer. 